\title{
O que pacientes e profissionais de saúde precisam saber sobre a Internet?
}

What patients and health professionals need to know about Internet?

\begin{abstract}
Maria Cristiane Barbosa Galvão
Doutora em Ciência da Informação pela Universidade de Brasília - UnB. Professora Doutora na Faculdade de Medicina de Ribeirão Preto da Universidade de São Paulo - FMRP/USP.

E-mail: $\underline{\text { mgalvao@usp.br }}$
\end{abstract}

PLUYE, Pierre, GRAD, Roland, BARLOW, Julie. Look it up!: what patients, doctors, nurses, and pharmacists need to know about the Internet and primary health care. Montreal; Kingston; London; Chicago: McGill-Queen's University Press, 2017.

Considerando-se apenas o título do livro Look it up! (Procure!) percebe-se que a obra propõe uma aproximação com o grande público, mas o conteúdo do livro vai além, estabelecendo, em linguagem de fácil compreensão, múltiplas conexões entre os estudos do campo da saúde, da ciência da informação e das tecnologias da comunicação. Esta abordagem resulta em grande parte da experiência acadêmica e comunicacional de seus autores. Vejamos.

Pierre Pluye é médico, professor titular do Departamento de Medicina de Família e professor associado à Escola de Estudos da Informação da McGill University, no Canadá, bem como é membro da Academia Canadense de Ciências da Saúde. Sua experiência acadêmica abarca pesquisas empregando métodos mistos e revisões de estudos mistos sobre o uso de recursos informacionais, recuperação de informação, feedback dos usuários da informação no campo da saúde e uso de mídias sociais para disseminação da informação em saúde, com foco em médicos, enfermeiros, farmacêuticos, gestores, pacientes e público em geral (PLUYE et al.; 2014; GALVAO; PLUYE; RICARTE, 2017; SHERIF et al., 2018). O autor tem recebido vários prêmios relacionados ao desenvolvimento de seus estudos no campo da informação em saúde.

Roland Grad é médico, professor associado do Departamento de Medicina de Família e diretor do Programa Clínico Acadêmico da McGill University. Além disso, é membro da ForçaTarefa Canadense de Assistência Preventiva à Saúde. Suas pesquisas abordam o uso de informação em saúde na prática clínica cotidiana, bem com o uso de tecnologias da comunicação e recursos informacionais na educação médica (BADRAN; PLUYE; GRAD, 2015, 2017). Desde 2003, seu trabalho, em parceria com Pierre Pluye, para desenvolver e validar o Método de Avaliação da Informação (IAM) é financiado pelos Institutos Canadenses de Pesquisa em Saúde, pela Associação Médica Canadense e pela Associação Canadense de 
Farmacêuticos. O IAM tem sido uma ferramenta empregada em pesquisas sobre translação do conhecimento e para a compreensão de como os profissionais de saúde usam informações clínicas (PLUYE et al., 2009; GALVÃO et al., 2018).

Julie Barlow é jornalista, escritora e conferencista canadense. Tem escrito livros sobre história cotidiana, linguagem e cultura traduzidos para vários idiomas e distribuídos em vários países, entre os quais: Sessenta milhões de franceses não podem estar errados, O efeito bonjour, A história do espanhol, e A história do francês (BARLOW; NADEAU, 2016; NADEAU; BARLOW, 2003, 2006, 2013).

Considerando o perfil dos autores é possível imaginar que Look it up! não é um livro científico tradicional. A obra usa como recurso comunicacional a contação de histórias, onde os personagens são pacientes e profissionais de saúde que revelam suas inquietações sobre a Internet, usos da informação e tecnologias da comunicação em saúde. A contação de histórias é uma abordagem bastante usada no campo da saúde para a educação de pacientes, da população em geral, estudantes e profissionais da saúde, pois gera uma aproximação com o cotidiano e maior empatia (FRANK, 2015).

Roland Grad relata no livro que, por exemplo, nunca esquecerá o dia em que Anne, uma de suas pacientes, perguntou-lhe sem rodeios: "Por que eu devo me consultar com um médico que precisa procurar as coisas na Internet?" Esta pergunta, segundo os autores do livro, revela como um paciente se sente quando um médico pega um smartphone e começa a navegar na Internet no meio de uma consulta. Muitos pacientes provavelmente se sentem intrigados: " $O S$ médicos não deveriam aprender tudo o que precisam saber na faculdade de medicina?" Partindo de cenários como esse, o livro traz esclarecimentos muito importantes: "Os médicos não sabem tudo!". Há muita informação em saúde disponível na atualidade para que todos os profissionais de saúde possam acompanhar os resultados dos mais recentes estudos científicos e todas as revisões e atualizações de diretrizes clínicas para melhor diagnóstico, tratamento e prevenção em saúde. Logo, o acesso e o uso de recursos informacionais especializados em saúde e decisão clínica são essenciais na prática dos profissionais de saúde.

Uma das histórias do livro relata a divergência de decisões entre profissionais de saúde decorrente do não acesso à informação atualizada. Os autores relatam que Rachel, uma mulher de 32 anos, que estava grávida de seu quinto filho, tinha a plena certeza de que queria um parto vaginal. Anteriormente, ela teve dois partos vaginais normais, mas precisou fazer uma cesariana quando deu à luz a gêmeos em sua última gravidez. Após a cesariana, ela teve uma recuperação 
difícil e bem diferente das experiências anteriores com parto vaginal. Assim, a paciente queria, efetivamente, um parto vaginal. Clara, a médica de Rachel, entendeu perfeitamente sua opção, mas o hospital onde trabalhava não costumava realizar um parto vaginal após a mulher ter passado por uma cesariana. Assim, havia duas opções: transferir Rachel para outro hospital de referência a cerca de uma hora e 10 minutos de distância ou convencer os colegas de trabalho de que era seguro realizar um parto vaginal, após a mulher ter passado por uma cesariana. Para tanto, a médica fez uma busca bibliográfica sobre os riscos e benefícios do parto vaginal após uma cesariana e encontrou duas revisões sistemáticas da literatura atualizadas de alta qualidade. Com essas informações em mãos, foi possível convencer seus colegas de trabalho e atender a vontade da paciente. A partir desse caso, os autores discutem a importância dos profissionais de saúde acessarem recursos informacionais atualizados durante a prática clínica, inclusive para que impasses e divergências sejam facilmente solucionadas.

Finalmente, cabe ressaltar que, por meio dessas e de outras histórias, o livro evidencia os bastidores da assistência em saúde na atualidade e como a Internet, os recursos informacionais em suporte digital e outras tecnologias de comunicação vêm transformando a vida de pacientes e a atuação dos profissionais de saúde. Mas e o futuro? O último capítulo do livro traz uma história instigante que se passa em 2035, quando se prevê uma assistência em saúde muito mais pautada em suportes e tecnologias digitais, ilustrando assim como os pacientes, o público, os estudantes e os profissionais de saúde devem se preparar para os próximos anos.

\section{Referências}

BADRAN, H.; PLUYE, P.; GRAD, R. Advantages and disadvantages of educational email alerts for family physicians: viewpoint. Journal of Medical Internet Research, v. 17, n. 2, p. $1-10,2015$.

When educational material is delivered: a mixed methods content validation study of the information assessment method. JMIR Medical Education, v. 3, n. 1, p. e4, 2017.

BARLOW, Julie, NADEAU, Jean-Benoit. The bonjour effect: the secret codes of French conversation revealed. New York: St. Martins' Press, 2016.

FRANK, B. L. et al. Telling stories, saving lives: creating narrative health messages. Health Communication, v. 30, p. 154-163, 2015.

GALVÃO, M. C. B. et al. Disseminating health evidence summaries to increase evidence use in health care. Revista de Saúde Pública, v. 409, p. 1-10, 2018. 
.; PLUYE, P.; RICARTE, I. L. M. Métodos de pesquisa mistos e revisões de literatura mistas: conceitos, construção e critérios de avaliação. InCID: Revista de Ciência da Informação e Documentação, v. 8, n. 2, p. 4, 2017.

NADEAU, Jean-Benoit, BARLOW, Julie. Sixty million Frenchmen can't be wrong: why we love France but not the French. Naperville: Sourcebooks, 2003.

The story of French. New York: St. Martins'ㄹess, 2006.

The story of Spanish. New York: St. Martins` Press, 2013.

PLUYE, P. et al. Development and content validation of the information assessment method for patients and consumers. Journal of Medical Internet Research, v. 16, n. 2, p. 1-15, 2014.

, et al. IAM: a comprehensive and systematic information assessment method for electronic knowledge resources. In: DWIVEDI, A. Handbook of research on IT management and clinical data administration in healthcare. Hershey: IGI, 2009. p. 521548.

SHERIF, R. EL et al. Reducing negative outcomes of online consumer health information: qualitative interpretive study with clinicians, librarians, and consumers. Journal of Medical Internet Research v. 20, p. 1-15, 2018. 